\title{
TRATAMENTO DE EFLUENTES INDUSTRIAIS ATRAVÉS DA UTILIZAÇÃO DE PLANTAS NA DESPOLUIÇÃO DA ÁGUA, ASSOCIADO À DECANTAÇÃ̃O E FILTRAÇÃO LENTA.
}

\section{TREATMENT OF INDUSTRIAL EFFLUENTS THROUGH OF THE USE OF PLANTS IN THE DEPOLLUTION OF WATER, ASSOCIATED WITH DECANTATION AND SLOW FILTRATION.}

\author{
Jonathan Borba ${ }^{1}$, Alexsander Novais Leste ${ }^{2}$, Elitânia Gomes Xavier ${ }^{3}$, Fânia Bailona Silva ${ }^{4}$, Anielly \\ Monteiro de Melo 5
}

\author{
${ }^{1}$ Técnico em química Graduando em Engenharia Mecânica - FACEG- jonathanborba20@hotmail.com \\ ${ }^{2}$ Técnico em química - alexsanderleste@hotmail.com \\ ${ }^{3}$ Eng. ${ }^{a}$ Agrônoma - Professora da Faculdade Evangélica de Goianésia - FACEG - elixavier15@yaroo.com.br \\ ${ }^{4}$ Química - coordenadora do Curso Técnico em Química Pronatec/mediotec e professora no Colégio Estadual da Polícia \\ Militar de Goias - José Carrilho. CEPMG - JC.-Faniabailona13@gmail.com \\ ${ }^{5}$ Química- Professora Colégio Estadual Jales Machado- anielly_@hotmail.com
}

\begin{abstract}
Resumo: A água é o elemento fundamental da vida. Seus múltiplos usos são indispensáveis a uma longa abrangência das atividades humanas, onde se destacam, entre outros, o abastecimento público e industrial, a irrigação agrícola, a produção de energia elétrica e as atividades de lazer e recreação. A água potável após a utilização humana apresenta suas características físicas, químicas e biológicas alteradas se transformando em efluentes. O uso de plantas na despoluição dos mesmostem conquistado significativo interesse científico. Portanto este estudo teve como objetivo avaliar o desempenho vegetal juntamente com a decantação e filtração no tratamento de efluentes, aproveitando suas características de retenção e eliminação de nutrientes. Foi utilizada no sistema a planta aquática (Eichhornia crassipes (mart.) solms) popularmente conhecida como aguapé além de bananeiras (Musa spp) e taiobas (Xanthosoma sagittifolium (L.) Schott) por meio de hidroponia, o meio de tratamento foi mantido em repouso proporcionando a decantação das partículas mais pesadas. Após a etapa de decantação e ação vegetal o efluente foi filtrado através de camadas de areia e brita. Avaliadas as propriedades físico-químicas do efluente bruto como: Turbidez, $\mathrm{pH}$, condutividade elétrica, cloretos, sólidos totais, temperatura e análises microbiológicas sendo comparadas com os resultados de cada etapa do sistema e com a legislação atual CONAMA No 430/2011 para lançamento de efluentes. Constatou-se a eficiência do meio com relação aos parâmetros analisados como redução de turbidez $(82,7 \%)$, sólidos totais $(97 \%)$, condutividade elétrica $(98 \%)$ e cloretos $(92 \%)$. Os índices de PH e temperatura apresentaram pouca variação e houve diminuição no número de bactérias patogênicas. Ao utilizar plantas, princípios de decantação e filtros de areia e brita foi possível obter resultados satisfatórios quanto ao tratamento de efluentes de laticínios.
\end{abstract}

Palavras-Chave: Efluentes, tratamento, aguapé, decantação, filtração.

\begin{abstract}
Water is the fundamental element of life. Its multiple uses are indispensable to a long range of human activities, which include, among others, public and industrial supplies, agricultural irrigation, electric energy production and leisure and recreation activities. Drinking water after human use has its altered physical, chemical and biological characteristics transforming into effluents. The use of plants in their depollution has gained significant scientific interest. Therefore, this study had as objective to evaluate the vegetal performance along with the decantation and filtration in the treatment of effluents, taking advantage of its characteristics of retention and elimination of nutrients. It was used in the system the aquatic plant (Eichhornia Crassipes (mart.) solms) popularly known as aguapé besides banana trees (Musa spp) and taiobas (Xanthosoma sagittifolium (L.) Schott) by means of hydroponics, the treatment medium was maintained at rest to allow the decantation of the heavier particles. After the decantation stage and plant action, the effluent was filtered through layers of sand and gravel. The physicochemical properties of the raw effluent were evaluated as: Turbidity, $\mathrm{pH}$, electrical conductivity, chlorides, total solids, temperature and microbiological analyzes, being compared with the results of each stage of the system and with the current legislation CONAMA No. 430/2011 for launching effluents. It was verified the efficiency of the medium in relation to the analyzed parameters as reduction of turbidity $(82.7 \%)$, total solids $(97 \%)$, electrical conductivity (98\%) and chlorides (92\%). PH and temperature indices showed little variation and there was a decrease in the number of pathogenic bacteria. By using plants, settling principles and sand and gravel filters, it was possible to obtain satisfactory results regarding the treatment of dairy effluents.
\end{abstract}

Keywords: Effluents, treatment, aguapé, decantation, filtration. 


\section{INTRODUÇÃO}

A demanda por recursos hídricos no mundo tem aumentado em razão de alguns fatores, como o aumento populacional, a movimentação fabril e o uso da irrigação na agricultura. As indústrias além de apoderarem o segundo lugar no consumo de água com $22 \%$, também possuem uma grande incumbência na poluição desse recurso(BARROS \& AMIN, 2008).

A contaminação do meio ambiente como resultado dos processos de produção teve seu auge a partir da revolução industrial. O uso da natureza para geração de lucros e benefícios privados favorece o surgimento de problemas ambientais, a menos que o meio possa se regenerar sozinho por meio da resiliência (DERISIO, 2012). Até 1970 o termo poluição era incomum em publicações e debates, com a exploração intensiva da natureza, motivada pela revolução verde e o crescimento do capitalismo que provocarama degradação do meio ambiente através da emissão progressivade elementos em excesso na natureza. Fizeram com que surgisse a preocupação ambiental principalmente nos países desenvolvidos(MANO et al., 2010).

Dentre os poluentes ambientais estão os efluentes industriais que quando despejados nos recursos hídricos, causam danos ao meio, podem atingir a saúde humana, contaminar espécies ou alterar vegetações (RIBEIRO \& BEGNINI, 2014). Os principais elementos existentes na composição das águas derivadas dos processos industriais são basicamente carboidratos, proteínas, óleos, gorduras, e substâncias utilizadas na limpeza da indústria e tubulações(POKRYWIECKI et al., 2013).

O setor alimentício possui características particulares, já que os alimentos possuem um ciclo curto e podem sofrer alterações de acordo com a forma de produção(RODRIGUES et al., 2008). Os laticínios têm como principal rejeito o soro, que muitas vezes recebe o mesmo destino dos outros resíduos líquidos sendo cerca de cem vezes mais poluidor que o efluente doméstico(RODRIGUES et al., 2016).

As plantas aquáticas aparecem como alternativa viável a problemática dos recursos hídricos, desempenham uma função importante dentro dos ecossistemas, elas afetam a química da água por meio da absorção de substâncias que podem ser nutrientes ou elementos tóxicos presentes na composição do fluido o que proporciona circunstâncias favoráveis para a sobrevivência de vários espécimes aquáticos, e serve como componente alimentar para esses seres (BRASIL et al.,2007).

O Eichhornia crassipes popularmente conhecido como aguapé ou jacinto d'água, é uma planta aquática flutuante podendo ser livre ou enraizada quando em contato com a margem. É uma planta resistente natural da América do Sul, sua reprodução e acelerada por meio da divisão dos rizomas, sementes ou estolões (SOUZA, 2013). O Eichhornia faz parte do seleto grupo de espécies com potencial de despoluição de águas cinza e resíduos líquidos industriais, absorvem nutrientes e outros elementos(MEES et al., 2009).

O aguapé assim como outras macrófitas aquáticas pode ser utilizado como redutor de 
bactérias patogênicas, atuando como biofiltros para despoluição de efluentes(DIAS et al., 2016). Quando o cultivo do aguapé acontece da maneira exata, levando em conta os cuidados e promovendo a manutenção, ele age como despoluidor. Entretanto o crescimento descontrolado da macrófita sem o manuseio apropriado pode resultar em problemas ambientais.

Sabei \& Bassetti (2013) apontam que outra espécie capaz de atuar na reciclagem das águas em conjunto com o Eichhornia é a bananeira (Musa spp) que por sua vez realiza o processo de evapotranspiração. Esse método libera grandes quantidades de água na atmosfera. As bananeiras já são utilizadas no tratamento de esgotos, além de recuperar a água, realizam a compostagem da matéria orgânica. A evapotranspiração depende muito da umidade e da irradiação solar, desta forma outras plantas podem ser adicionadas no sistema visando maior aproveitamento e eficiência, como por exemplo, as taiobas (Xanthosoma sagittifolium).

Conforme Dias et al.,(2010) a hidroponia é uma técnica de cultivo de plantas sem a presença de solo, apenas água e nutrientes necessários para o progresso das espécies. O cultivo hidropônico é uma alternativa para livrar-se de efluentes salinos, uma vez que leva em conta que as plantas são mais tolerantes a salinidade quando implantadas em meios hidropônicos, essa tolerância e muito maior se comparada com o plantio tradicional.

As Estações de tratamento de água (ETA), no que diz respeito a processos se assemelham as indústrias, recebe uma matéria prima (água) e a transforma por meio de etapas em um produto desejado neste caso a água tratada(ACHON et al.,
2008). Nos tanques de decantação as partículas são depositadas no fundo por meio da influência da gravidade, isso acontece porque os flocos são mais pesados que a água, o efeito é a formação de um efluente mais claro e uma parte em estado sólido decantada. As partículas que passam pela decantação são retidas na filtração(FILHO et al., 2011).

Objetivou-se com essa pesquisa avaliar o desempenho das plantas de aguapé, bananeiras e taiobas juntamente com a decantação e filtração no tratamento de águas poluídas e efluentes industriais, aproveitando suas características de retenção e eliminação de nutrientes.

\section{MATERIAIS E MÉTODOS}

O experimento foi realizado na indústria de laticínios Cooperativa Agropecuária de Goianésia Ltda. - CAGEL inscrita no CNPJ 02.297.711/0001/03, situada no município de Goianésia região do Vale do São Patrício com coordenadas geográficas latitude (S) - 15²18'17.0; longitude (W) $-49^{\circ} 05^{\prime} 45.4$

A lagoa de decantação possui $40 \mathrm{~m}$ de comprimento, $30 \mathrm{~m}$ de largura e $2,5 \mathrm{~m}$ de profundidade, de acordo com os cálculos realizados relacionados a volume, constata-se que a lagoa possui atualmente cerca de 3000000 de litros de água contaminada.

O sistema de tratamento foi subdividido em etapas que foram: tratamento realizado com plantas, decantação e filtragem por meio de filtros de areia e brita.

Montagem do tanque 
Para realização do experimento foi utilizado um tanque metálico de $04 \mathrm{~m}$ de comprimento, $1,2 \mathrm{~m}$ de largura e 0,7 $\mathrm{m}$ de profundidade, com capacidade de 3360 litros. O mesmo foi colocado nas proximidades da lagoa de decantação, o tanque foi higienizado manualmente com produtos de limpeza da forma devida para evitar interferências nos resultados.

Em seguida a água foi colocada no tanque coletada diretamente da lagoa até metade de sua capacidade total. Com a água nos limites desejados iniciou- se o processo de tratamento com as plantas. Foi colocado no tanque aguapés, bananeiras e taiobas, as duas últimas por meio de hidroponia.

\section{Material Vegetal}

As plantas utilizadas foram coletadas na chácara ipê e transportadas com antecedência. Antes de serem introduzidos no tanque passaram por um período de aclimatação de 15 dias dentro da própria lagoa de decantação.

Após o último dia de aclimatação foram colocadas dentro do tanque com água da lagoa de decantação, e foram mantidas por 30 dias em contato com o efluente industrial. No decorrer dos 45 dias de estudo houve o monitoramento diário durante as duas primeiras semanas e a partir daí o acompanhamento passou a ser semanal.

O complexo foi mantido em repouso para que as plantas pudessem exercer seu papel na limpeza da água e promover a decantação espontânea. O tanque foi coberto com telas para que não houvesse a proliferação de mosquitos e consequentemente viesse a causar danos a saúde dos trabalhadores da indústria.
Uma lona foi colocada acima das telas para evitar que a água da chuva adentrasse no meio de tratamento e pudessem influenciar nos resultados. Filtros de areia

Com o fim da primeira etapa com plantas além do efeito da decantação, o efluente foi destinado à próxima etapa do sistema: a filtração. A água do tanque com as plantas foi liberada e passou por um filtro feito com galão de água mineral (capacidade de 20 l) composto por camadas de areia e brita.

Análises físico- químicas e microbiológicas

Foram definidas as principais condições físico-químicas do efluente bruto, a descrição se deu através das análises de turbidez, condutividade elétrica, $\mathrm{pH}$, sólidos totais e cloretos de acordo com os métodos indicados por(RICE et al., 2012). E foram ainda realizadas analises de coliformes e mesófilos.

As análises foram realizadas nos laboratórios da CAGEL-Cooperativa agropecuária de Goianésia, Clinefro e no I

nstituto Tecnológico Governador Otávio Lage.

Turbidez

Para a análise de turbidez das amostras foi utilizado turbidímetro (Alfakit) de bancada. Transferiu-se a amostra do efluente para o bécker e realizou-se a averiguação.

Determinação do Potencial hidrogeniônico $(\mathrm{pH})$

Para determinar os valores de $\mathrm{pH}$ da amostra utilizou-se pHmetro (M.S tecnopan FTP. 905). As amostras foram transportadas em frascos 
de polietileno e levadas imediatamente ao laboratório, para análise.

Condutividade elétrica

A condutividade elétrica da amostra de efluente foi determinada por meio de um condutivímetro (Marconi FCTP. 906). As amostras foram transportadas em frascos de polietileno e levadas imediatamente ao laboratório, para quantificação.

\section{Sólidos totais}

A determinação de sólidos totais ocorreu por meio da multiplicação do valor encontrado na análise de condutividade elétrica (leitura do condutivimetro) e uma constante variável de acordo com o tipo de água analisada sendo que o valor indicado para amostras sem tratamento é $(0,75)$.

\section{Cloretos}

A análise foi executada pelo método de Mohr. Pipetou-se $50 \mathrm{~mL}$ da amostra em erlenmeyer, adicionando $1 \mathrm{~mL}$ de cromato de potássio. Seguidamente realizou-se a titulação com nitrato de prata.

\section{Coliformes}

Análise feita através da redução da concentração de $1 \mathrm{~mL}$ da amostra de água em três tubos de ensaio com água peptonada, nas concentrações $\left(10^{-1}, 10^{-2}, 10^{-3}\right)$. Para análise de coliformes foi utilizado como meio de cultura a solução de Violet Red Bile Agar-VRB.

Feito procedimento as placas foram colocadas em estufa FANEM 502 por 48 horas a $35{ }^{\circ} \mathrm{C}$ e, configurou-se a fase de determinações. Após 48 horas foi coletada uma amostra para confirmação de proliferação. A amostra foi colocada em seis tubos de ensaio com caldo verde brilhante, correspondentes à concentração inicial e colocada em estufa por mais 48 horas desta vez a $45^{\circ} \mathrm{C}$. Por fim foi realizada a contagem das colônias.

\section{Mesófilos}

A determinação dos mesófilos foi feita através da redução da concentração de $1 \mathrm{~mL}$ da amostra de agua em três tubos de ensaio com água peptonada, nas concentrações $\left(10^{-1}, 10^{-2}, 10^{-3}\right)$. O meio de cultura utilizado foi o ágar Baird-Parker. Feito procedimento as placas foram colocadas em estufa FANEM 502 por 48 horas a $35^{\circ} \mathrm{C}$, ao fim constatada a proliferação realizou-se a contagem das colônias formadas no meio.

\section{RESULTADOS}

Durante o período de tratamento do efluente houve o aumento de biomassa por parte dos aguapés, mas não em quantidades que fossem necessárias a remoção do excesso (Figura 1). 


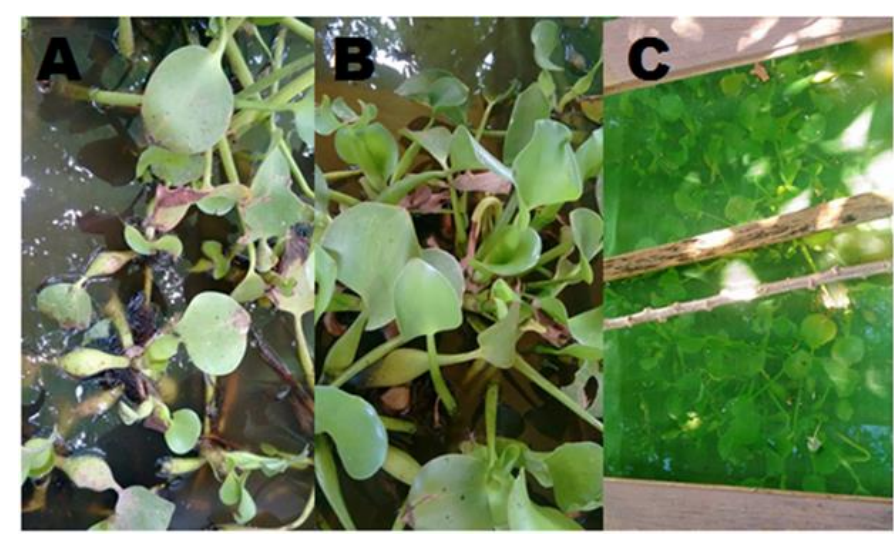

Figura 1: Aumento da biomassa do aguapé. Fonte: Arquivo do autor.

As Taiobas e bananeiras, conforme mostra na água o que indica a eficiência do método a Figura 02, também apresentaram hidropônico. Os brotos precisaram ser cortados desenvolvimento de brotos e folhas e para evitar o contato com a tela de proteção (Figura comprovaram o auto índice de nutrientes presentes 2).

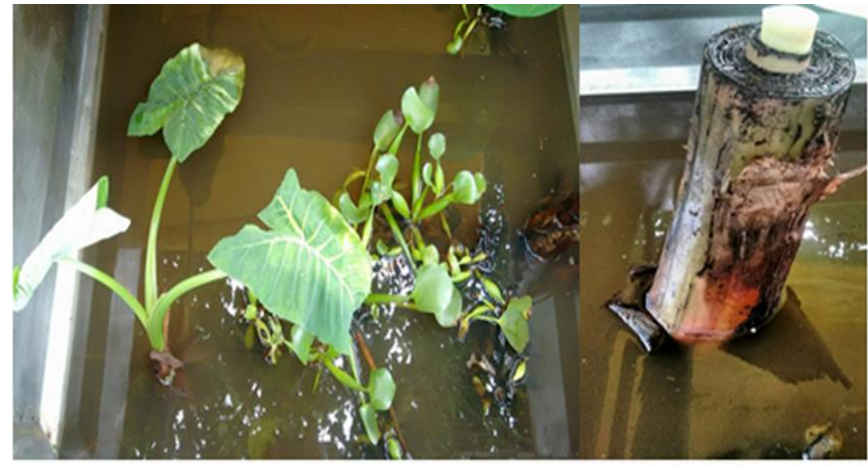

Figura 2: Taiobas, bananeiras e aguapés em imersão no tanque de tratamento.

Fonte: Arquivo do autor.

Os dados médios do efluente bruto, do efluente tratado no tanque com plantas e do efluente após a filtração estão descritos na tabela 1.

Tabela 1: Dados obtidos nas análises físico- químicas e microbiológicas em cada etapa do tratamento. Fonte: Arquivo do autor

\begin{tabular}{|c|c|c|c|c|c|c|c|c|}
\hline \multirow[b]{2}{*}{$\begin{array}{l}\text { Etapas de } \\
\text { tratamento }\end{array}$} & \multicolumn{8}{|c|}{ Análises físico-químicas e microbiológicas (média) } \\
\hline & $\mathrm{pH}$ & $\begin{array}{l}\text { Turbidez } \\
\text { (NTU) }\end{array}$ & $\begin{array}{c}\text { Condutividade } \\
\text { elétrica } \\
(\mu \mathrm{S} / \mathrm{cm})\end{array}$ & $\begin{array}{l}\text { Sólidos } \\
\text { totais } \\
\text { (PPM) }\end{array}$ & $\begin{array}{l}\text { Cloretos } \\
(\mathrm{mg} / \mathrm{l})\end{array}$ & $\begin{array}{c}\text { Coliformes } \\
\text { (UFC/ml) } \\
(\mathrm{NMP} / 100 \\
\mathrm{ml}) \\
\end{array}$ & $\begin{array}{l}\text { Mesófilos } \\
\text { (UFC/ml) }\end{array}$ & $\begin{array}{c}\text { Temperatura } \\
\left({ }^{\circ} \mathrm{C}\right)\end{array}$ \\
\hline $\begin{array}{l}\text { Efluente } \\
\text { bruto }\end{array}$ & 7,1 & 255,31 & 710,5 & 533 & 177,5 & $\begin{array}{c}325^{4} \\
240\end{array}$ & $201^{4}$ & 26,5 \\
\hline $\begin{array}{l}\text { Efluente } \\
\text { tratado } \\
\text { com plantas } \\
\text { e } \\
\text { decantação }\end{array}$ & 7,4 & 46,98 & 21,47 & 16,10 & 173,95 & $\begin{array}{l}65^{4} \\
220\end{array}$ & $\begin{array}{l}\text { Não houve } \\
\text { proliferação }\end{array}$ & 27 \\
\hline $\begin{array}{l}\text { Efluente } \\
\text { filtrado }\end{array}$ & 7,3 & 44,22 & 14,5 & 10,88 & 14,2 & $\begin{array}{l}61^{4} \\
170\end{array}$ & $\begin{array}{l}\text { Não houve } \\
\text { proliferação }\end{array}$ & 26 \\
\hline
\end{tabular}


Os dados médios definem o resultado da análise do efluente bruto coletado da lagoa de decantação. Os parâmetros analisados $\mathrm{pH} 7,1$, turbidez 255,31 NTU, condutividade elétrica 710,5 $\mu \mathrm{S} / \mathrm{cm}$, sólidos totais $533 \mathrm{PPM}$, cloretos 177,5 $\mathrm{mg} / \mathrm{I}$, coliformes $325^{4} \mathrm{UFC} / \mathrm{ml} 240 \mathrm{NMP} / 100 \mathrm{ml}$, mesófilos $201^{4} \mathrm{UFC} / \mathrm{ml}$ e temperatura $26,5^{\circ} \mathrm{C}$.

Os dados médios definem o resultado da análise do efluente tratado no tanque de plantas associado a decantação, sendo os parâmetros analisados $\mathrm{pH}$ 7,4, turbidez 46,98 NTU, condutividade elétrica $21,47 \mu \mathrm{S} / \mathrm{cm}$, sólidos totais 16,10 PPM, cloretos $173,95 \mathrm{mg} / \mathrm{l}$, coliformes $65^{4}$ $\mathrm{UFC} / \mathrm{ml} 220 \mathrm{NMP} / 100 \mathrm{ml}$, nesta etapa não houve proliferação de mesófilos e temperatura $27^{\circ} \mathrm{C}$.

Os dados médios definem o resultado da análise do efluente tratado no tanque de plantas

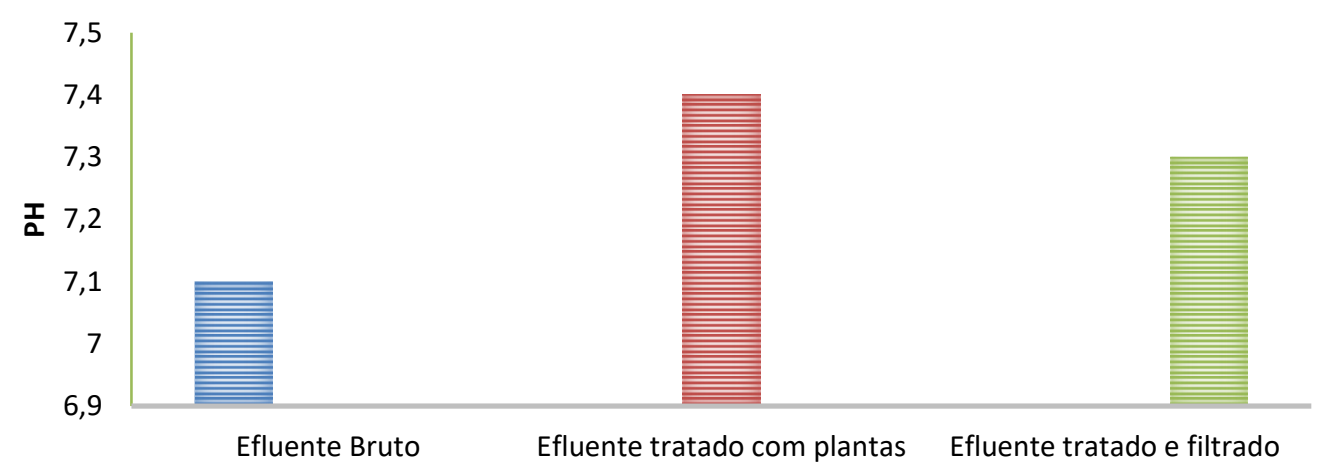

Figura 3: Valores de $\mathrm{pH}$ nas etapas de tratamento.

Os valores de $\mathrm{pH}$ encontrados são semelhantes aos de Dias et al., (2016), que pesquisaram três espécies de macrófitas aquáticas para tratamento do efluente coletado no riacho Mussuré, em que antes e após o tratamento o pH manteve-se neutro e apresentou valores entre $6 \mathrm{e}$ 7, a macrófita que apresentou melhor resultado foi o aguapé com pH 7. associado à decantação e filtrado com a utilização do filtro de areia e brita, sendo os parâmetros analisados pH 7,3, turbidez 44,22 NTU, condutividade elétrica $14,5 \mu \mathrm{S} / \mathrm{cm}$, sólidos totais 10,88 PPM, cloretos 14,2 mg/l, coliformes $61^{4}$ $\mathrm{UFC} / \mathrm{ml} 170 \mathrm{NMP} / 100 \mathrm{ml}$, nesta etapa não houve proliferação de mesófilos e temperatura $26^{\circ} \mathrm{C}$.

Valores de $\mathrm{pH}$

A variação dos valores de $\mathrm{PH}$ encontrados nas análises indicou que os níveis se mantiveram próximos sendo $(7,1<\mathrm{PH}<7,4) \quad$ conforme apresenta Figura 3. Os parâmetros do pH atendem aos estipulados pela Resolução CONAMA N ${ }^{\circ}$ 430/2011 onde e considerado ideal para o lançamento de efluentes a faixa entre 5 e 9 .
Turbidez

É possível constatar a expressiva diminuição da turbidez, o efluente bruto apresentou valores acima de 250 NTU, a redução para 46,98 NTU ocorrida no tanque é justificada pela ação vegetal, mas principalmente devido ao processo de decantação. Os valores ainda puderam ser melhorados após a filtração, com a retenção de resíduos e impurezas, foram atingidos 44,22 NTU e redução de $82,7 \%$ com o uso de todas as etapasde acordo com a Figura 4. 


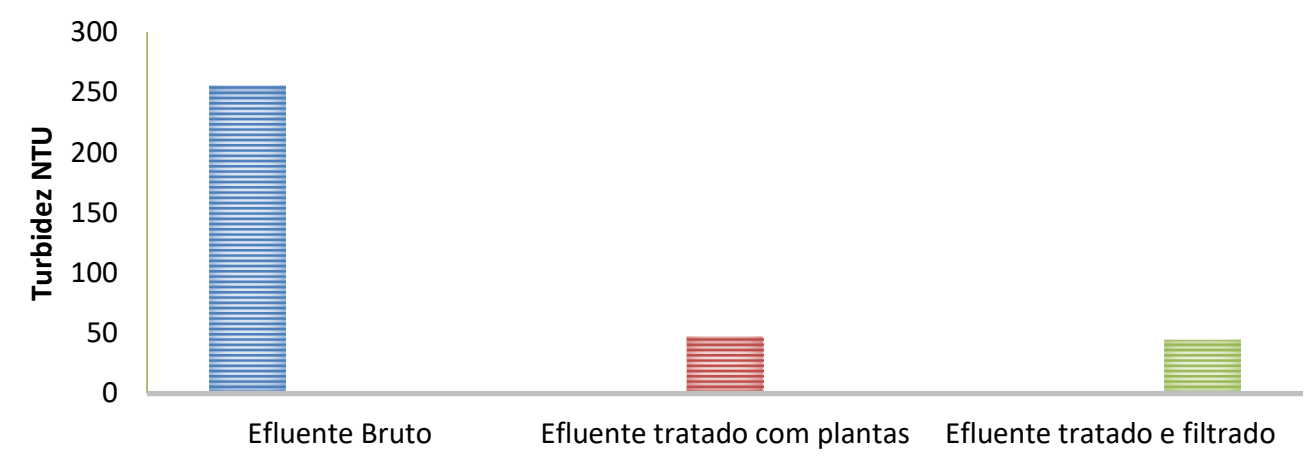

Figura 4: Valores de turbidez (NTU) nas etapas de tratamento.

A redução de turbidez no estágio de quantidade de elementos presentes na água capazes decantação se assemelha a de Cardoso et al (2008) de conduzir eletricidade(CARVALHO et al., que em seu estudo de otimização do tempo de 2000). Assim como nas análises de turbidez, houve mistura e decantação encontrou valores acima de uma considerável redução na condutividade $80 \%$ na remoção da turbidez.

Condutividade elétrica

A condutividade elétrica está ligada ao elétrica do efluente tratado $96 \%$ de eficiência no sistema com plantas e 98\% após a filtragem (Figura aumento ou redução da turbidez devido à $5)$.

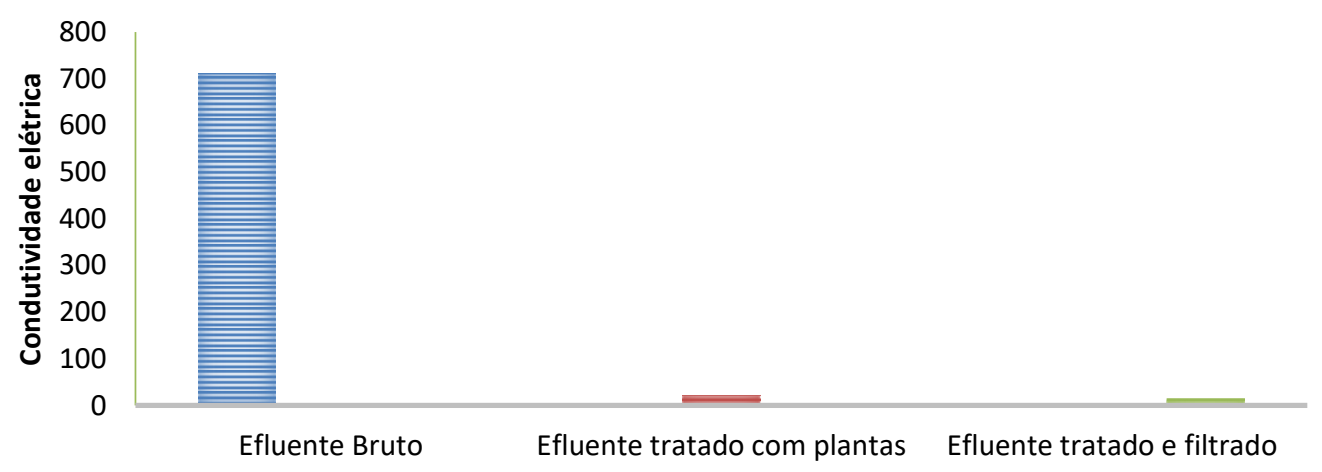

Figura 5: Valores de condutividade elétrica nas etapas de tratamento.

No estudo de França et al(2014) com a utilização de macrófitas aquáticas no tratamento de efluentes domésticos os valores de condutividade elétrica apresentaram pouca variação de $20,11 \%$ a $23,60 \%$. Os dados reforçam que a considerável redução na condutividade elétrica está associada à decantação e a remoção da turbidez. Vale ressaltar que o aguapé também atua na absorção de íons.

Sólidos Totais
O maior valor de ST encontrado corresponde à análise do efluente bruto sem tratamento, ocasionado por coletas de amostras com cargas maiores de resíduos provenientes do processo industrial. A amostra do tanque de plantas apresentou redução de 97\%, valor relacionado à atividade vegetal e ao processo de decantação. Calijuri et al(2009) conduziu o estudo realizado na unidade experimental de tratamento de esgotos e utilização de efluentes da violeira, 
onde por meio do comportamento de wetlands verificou a redução média de $70 \%$ dos sólidos totais.

Com a filtragem encerrou-se o experimento com resultado de 10,88 PPM (Figura
6). Dentre as condições de lançamento de efluentes abordados pela Resolução CONAMA N ${ }^{\circ}$ 430/2011, não são especificados valores para sólidos totais, entretanto de acordo com a legislação não deve haver materiais flutuantes.

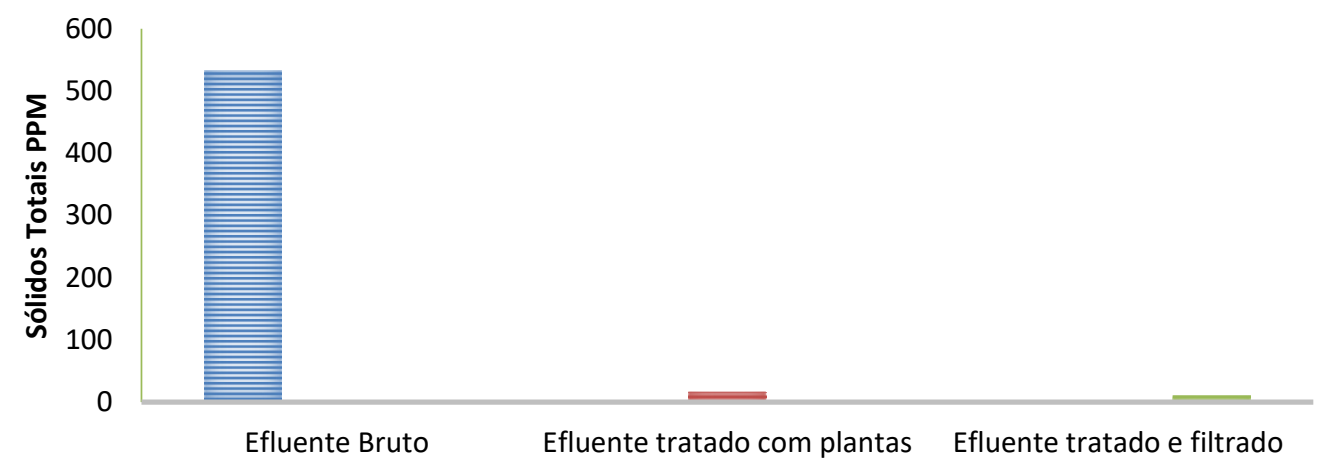

Figura 6: Valores de sólidos totais (PPM) nas etapas de tratamento.

Cloretos

As concentrações de cloretos foram reduzidas em ambas as etapas de tratamento, no tanque de plantas a diferença para o efluente bruto foi de $177,5 \mathrm{mg} / \mathrm{L}$ para 173,95 mg/L. Dias et al., (2016) compararam três macrófitas aquáticas quanto ao potencial de tratamento de efluentes, para cloretos o aguapé apresentou maior eficiência partindo de 47,5 mg/l e chegando 37,3 mg/l, após
7 dias de contato, associam a redução a absorção dos cloretos por parte da macrófita que os elimina através da evapotranspiração. Os valores obtidos após a filtragem do efluente representaram diminuição de $92 \%$ dos cloretos presentes na água reduzindo os valores para 14,2 mg/L (Figura 7). A Resolução CONAMA No 430/2011 não estabelece padrões específicos para cloretos.

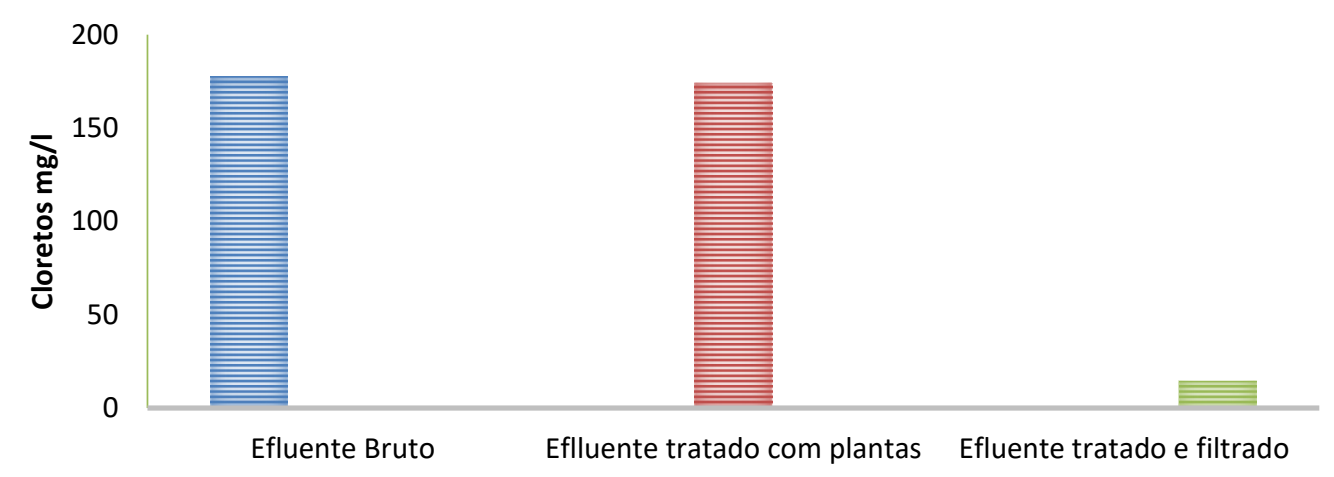

Figura 7: Valores de cloretos $(\mathrm{mg} / \mathrm{L})$ nas etapas de tratamento.

\section{Microbiologia}

A confirmação da presença de coliformes ocorre pela formação de gás e mudança de coloração no interior dos tubos de ensaio com amostragem de bactérias, visto antes (Figura 8 A) e depois (Figura 8 B).Os resultados microbiológicos atenderam ao regulamento, o uso de aguapés plantas aquáticas com potencial redutor de 
bactérias patogênicas ocasionou a redução dos coliformes já no tanque de tratamento dos valores de $325^{4} \mathrm{UFC} / \mathrm{ml} 240 \mathrm{NMP} / 100 \mathrm{ml}$ para $65^{4}$ $\mathrm{UFC} / \mathrm{ml} 220 \mathrm{NMP} / 100 \mathrm{ml}$.Após filtragem foi atingido o valor de $61^{4} \mathrm{UFC} / \mathrm{ml} 170 \mathrm{NMP} / 100 \mathrm{ml}$ remoção final de $81,2 \%$, podendo ainda considerar os filtros de areia como outro possível redutor de bactérias patogênicas.

Spósito (2013) atenta para o complexo radicular do aguapé que age como um filtro mecânico, aderindo o material particulado. Assim reduz a turbidez e o índice de coliformes.Calijuri et al(2009) registrou a redução entre 99,20\% e $99,79 \%$ da concentração de coliformes. Em ambos os métodos de tratamento não houve proliferação de mesófilos o que ressalta a eficiência microbiológica, visto que no efluente bruto houve o desenvolvimento de $201^{4} \mathrm{UFC} / \mathrm{mL}$.
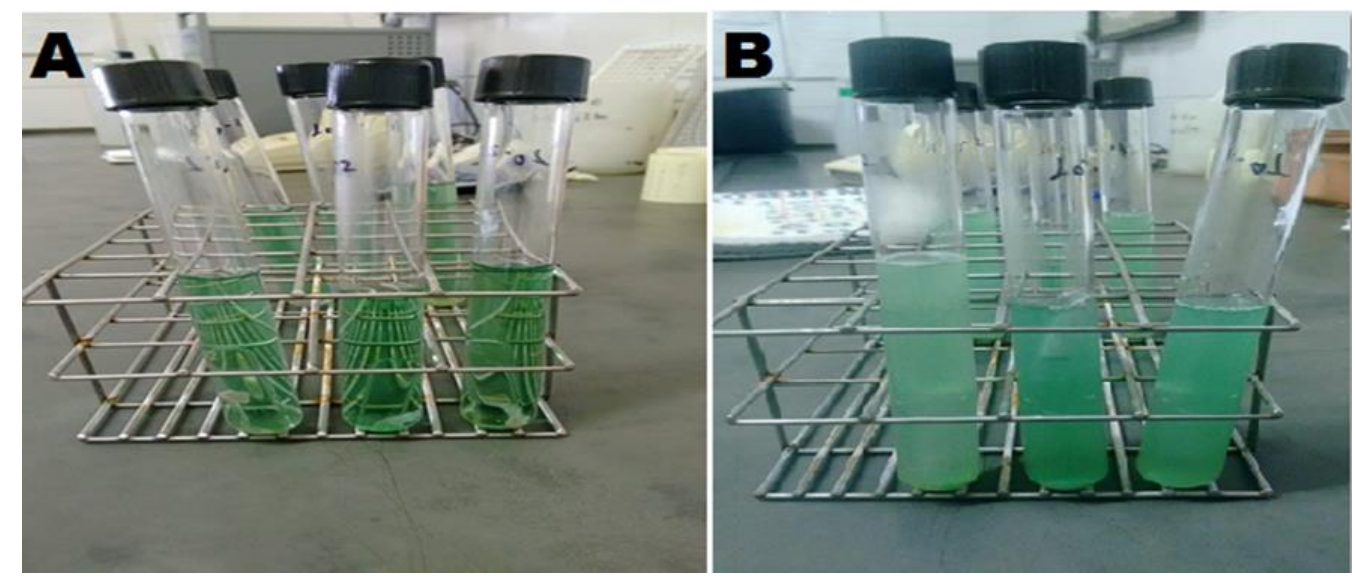

Figura 8: Confirmação da presença de coliformes.

Fonte: Arquivo do autor.

Variação de temperatura

A temperatura das amostras não apresentou variações, $26,5{ }^{\circ} \mathrm{C}$ no efluente da lagoa de decantação, $27^{\circ} \mathrm{C}$ no tanque de plantas e $26{ }^{\circ} \mathrm{C}$ após a filtração. $\mathrm{O}$ aumento da temperatura no tanque de plantas ocorreu devido ao material metálico do recipiente ser um bom condutor térmico. As mudanças de temperatura não ultrapassam os limites definidos pela Resolução CONAMA No 430/2011 que exige para o lançamento de efluente temperatura inferior a $40{ }^{\circ} \mathrm{C}$ e variação de até $3^{\circ} \mathrm{C}$ no corpo receptor.

DQO e DBO
Segundo os dados apresentados por Mees(2006) em ambos foi identificada a eficiência principalmente nos meses iniciais das macrófitas junto ao efluente, além disso, houve o aumento do oxigênio dissolvido. Isto se da graças ao desenvolvimento e crescimento das plantas associados à absorção da poluição.

Conforme as plantas diminuem a frequência de crescimento, a retirada das substâncias poluentes também reduz. Sendo que nos meses de chuva e com temperaturas superiores a $20{ }^{\circ} \mathrm{C}$ a eficácia foi maior. A média de remoção de DQO foi de 26,3\% e máxima de $77,2 \%$, já a média de remoção para DBO foi de 
$32,5 \%$ e máxima de $77,8 \%$ conforme a legislação a redução mínima deve ser de $60 \%$.

\section{CONCLUSÃO}

Ao utilizar plantas, princípios de decantação e filtros de areia e brita é possível obter resultados satisfatórios quanto ao tratamento de efluentes industriais em especial os de laticínios.

O método adotado reduziu a turbidez, sólidos totais, cloretos, condutividade elétrica e houve diminuição no número de bactérias patogênicas. Os índices de $\mathrm{pH}$ e temperatura apresentaram pouca variação estando em conformidade com a legislação.

De acordo com os resultados analisados o Eichbornia crassipes reduz os níveis de matéria orgânica (DQO e DBO) e aumenta as taxas de oxigênio dissolvido.

O sistema desenvolvido se apresenta como um biofiltro saudável e de bom desempenho, além de uma alternativa sustentável e de baixo custo.

\section{REFERÊNCIAS BIBLIOGRÁFICAS}

ACHON, C. L.; BARROSO, M. M.; CORDEIRO, J. S. Leito de drenagem: sistema natural para redução de volume de lodo de estação de tratamento de água. Eng. Sanit. Ambient. 2008; 13: 54-62.

BARROS, F. G. N.; AMIN, M. M. A. Água: um bem econômico de valor para o Brasil e o mundo. Revista Brasileira de Gestão e Desenvolvimento Regional. 2008; 4: 75108.

BRASIL, M. DA S.; MATOS, A. T. DE; SOARES, A. A. Plantio e desempenho fenológico da taboa (thypha sp.) utilizada no tratamento de esgoto doméstico em sistema alagado construído. Eng. Sanit. ambient.
2007; 12: 266-272.

BRASIL, Resolução CONAMA no 430, de 13 de maio de 2011. Dispõe sobre as condições e padrões de lançamento de efluentes. Publicada no D.O.U n ${ }^{\circ} 92$ de 16 de maio de 2011.

CALIJURI, M. L.; BASTOS, R. K. X.; MAGALHÃES, T. B.; CAPELETE, B. C.; DIAS, E. H. O.Tratamento de esgotos sanitários em sistemas reatores UASB / wetlands construídas de fluxo horizontal: eficiência e estabilidade de remoção de matéria orgânica, sólidos, nutrientes e coliformes. Eng Sanit. Ambient. 2009; 14: 421-430.

CARDOSO, K. C.; BERGAMASCO, R.; COSSICH, E. S.; MORAES, L. C. K. Otimização dos tempos de mistura e decantação no processo de coagulação/floculação da água bruta por meio da Moringa oleifera Lam.Acta Sci.Technol. 2008; 30: 193-198.

CARVALHO, A. R; SCHLITTLER, F. H. M.; TORNISIELO, V. L. Relações da atividade agropecuária com parâmetros físicos químicos da água. Quim. Nova. 2000; 23: 618-622.

DERISIO, J. C. Introdução ao controle de poluição ambiental. 4 nd ed. São paulo: Oficina de textos, 2012.

DIAS, F. S.; NASCIMENTO, J. P. A. DO; MENESES, J. M. DE. Aplicação de macrófitas aquáticas para tratamento de efluente doméstico. Rev. Ambient.2016; 2: 106-115.

DIAS, N. S.; LIRA, R. B.; BRITO, R. F.; SOUSA NETO, O. N.; FERREIRA NETO, M.; OLIVEIRA, A. M. Produção de melão rendilhado em sistema hidropônico com rejeito da dessalinização de água em solução nutritiva.Rev. Bras. Eng. Agríc. Ambient. 2010;14: 755-761.

FILHO, M. A. F. L.; ZANINI, J. R.; SILVA, E. R. S.; CAZETTA, J. O.; FERRAUDO, A. S. Sistema com aeração, decantação e filtragem para a melhoria da qualidade de água em irrigação localizada. Eng. Agríc. 2011; 31: 506-519.

FRANÇA, J. B. DE A; MORAES, T. V.; VAZ, 
D. DA C.; FERREIRA, A. A.; SOARES, F. A. L. Tratamento de efluente doméstico com macrófitas aquáticas para reúso na fertirrigação. Irriga. 2014; 1: 85-93.

MANO, E. B.; PACHECO, É. B. A. V.; BONELLI, C. M. C. Meio Ambiente, Poluição e Reciclagem. 2nd ed.São paulo: Blucher; 2010.

MEES, J. B. R. Uso de Aguapé (Eichhornia Crassipes) em Sistema de Tratamento de efluente de matadouro e frigorífico e avaliação de sua compostagem (Dissertação). Cascavel: Universidade Estadual do Oeste do Parana, 2006.

MEES, J. B. R.; DAMASCENO, S.; BOAS, M. A.V.;FAZOLO, A.; SAMPAIO, S. C. Estabilização da biomassa de aguapé através da compostagem com águas resíduárias de suínos e resíduos de frigorífico. Ciênc. Agrár. 2009; 30: 709-716.

POKRYWIECKI, T. S.; GUMY, M. P.;TONIAL, I. B. POKRYWIECK, J. C.Avaliação do processo de tratamento de efluentes de laticínios. Rev. Acad. Ciênc. Agrar. Ambient. 2013;11: 155-161.

RIBEIRO, H. B.; BEGNINI, B. C. Plano para redução de carga poluidora em indústria de lacticínios.Saúde e meio ambiente. 2014; 3:19-30.

RICE, E. W.; BAIRD, R. B.; EATON, A. D.; CLESCERE, L. S. Standard methods for the examination of water and wastewater. 22nd ed. New York: APHA; 2012.

RODRIGUES, A. C.; BAUM, C. A.; FORMENTINI, J.; SCHMACHTENBERG, N.; TREVISAN, G. M.; SILVA, A. C. G.Avaliação do processo de compostagem utilizando lodo de Estação de Tratamento de Efluentes de laticínio. Ciência e Natura. 2016; 38: 610 - 619 .

RODRIGUES, L. B.; SANTANA, N. B.; BONOMO, R. C. F.; SILVA, L. B. Apreciação ergonômica do processo de produção de queijos em indústrias de laticínios. Revista Produção Online. 2008; 8: 1-18.

SABEI, T. R.; BASSETTI, F. D. J. Alternativas ecoeficientes para tratamento de efluentes em comunidades rurais. Periódico Eletrônico Fórum Ambiental da Alta Paulista. 2013; 9: 487-503.

SOUZA, E. L. C.Impacto ambiental do uso do glyphosate no controle de aguapé (eichhornia crassipes) (Tese). Campinas, SP: Universidade Estadual de Campinas, faculdade de engenharia agrícola; 2013.

SPÓSITO, T. H. N.Parâmetros físico-químicos do efluente de ete do distrito urbano de Montalvão/SP manejado com aguapé (Dissertação).Presidente Prudente, SP:Universidade do Oeste Paulista; 2013. 